\title{
Advanced head and neck surgery training during the COVID-19 pandemic
}

\author{
Babak Givi MD ${ }^{1}$ (i) | Michael G. Moore MD $^{2} \quad \mid \quad$ Arnaud F. Bewley $\mathrm{MD}^{3}$ |

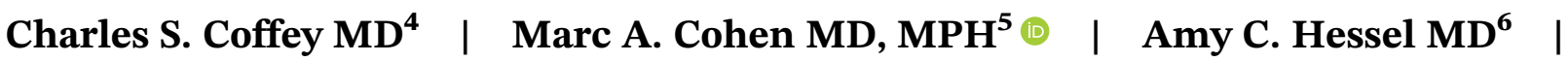 \\ Scharukh Jalisi MD $^{7} \quad$ Steven Kang MD $^{8}$ (1) ～Jason G. Newman MD $^{9}$ | \\ Liana Puscas MD, MHS ${ }^{10}$ | Maisie Shindo MD | Andrew Shuman MD $^{12}$ | \\ Punam Thakkar MD | Donald T. Weed MD $^{14}$ ～Ara Chalian MD ${ }^{9}$ \\ ${ }^{1}$ Department of Otolaryngology, NYU Langone Health, New York, New York \\ ${ }^{2}$ Department of Otolaryngology, Indiana University, Indianapolis, Indiana \\ ${ }^{3}$ Department of Otolaryngology, University of California, Davis, California \\ ${ }^{4}$ Department of Surgery, Division of Otolaryngology, University of California, San Diego, California \\ ${ }^{5}$ Head and Neck Service, Memorial Sloan-Kettering Cancer Center, New York, New York \\ ${ }^{6}$ Department of Head and Neck Surgery, MD Anderson Cancer Center, Houston, Texas \\ ${ }^{7}$ Department of Otolaryngology, Beth Israel Deaconess Medical Center, Boston, Massachusetts \\ ${ }^{8}$ Department of Otolaryngology, Ohio State University, Columbus, Ohio \\ ${ }^{9}$ Department of Otolaryngology, University of Pennsylvania, Philadelphia, Pennsylvania \\ ${ }^{10}$ Department of Head and Neck Surgery, Duke University, Durham, North Carolina \\ ${ }^{11}$ Department of Otolaryngology, Oregon Health and Science University, Portland, Oregon \\ ${ }^{12}$ Department of Otolaryngology, University of Michigan, Ann Arbor, Michigan \\ ${ }^{13}$ Division of Otolaryngology, The George Washington University, Washington, DC \\ ${ }^{14}$ Department of Otolaryngology, University of Miami, Coral Gables, Florida
}

Correspondence

Babak Givi, MD, NYU Langone Health, 160 E 34th Street, 7th Floor, New York, NY 10016.

Email: babak.givi@nyulangone.org

\begin{abstract}
Background: The COVID-19 pandemic has significantly impacted medical training. Here we assess its effect on head and neck surgical education.

Methods: Surveys were sent to current accredited program directors and trainees to assess the impact of COVID-19 on the fellow's experience and employment search. Current fellows' operative logs were compared with those of the 2018 to 2019 graduates.

Results: Despite reduction in operative volume, $82 \%$ of current American Head and Neck Society fellows have reached the number of major surgical operations to support certification. When surveyed, $86 \%$ of program directors deemed their fellow ready to enter practice. The majority of fellows felt prepared to practice ablative (96\%), and microvascular surgery (73\%), and 57\% have secured employment to follow graduation. Five (10\%) had a pending job position put on hold due to the pandemic.
\end{abstract}


Conclusions: Despite the impact of the COVID-19 pandemic, current accredited trainees remain well-positioned to obtain proficiency and enter the work-force.

KEYWOR D S

COVID-19, education, head and neck surgery, pandemic, surgical education

\section{1 | INTRODUCTION}

The American Head and Neck Society (AHNS) maintains as its mission statement to "advance education, research and quality of care for the head and neck oncology patient." ${ }^{1}$ The AHNS is the single largest organization in North America for the advancement of research and education in head and neck oncology. Chief among its educational mission is the certification of advanced head and neck surgery trainees and accreditation of high-quality head and neck fellowship training programs.

The pandemic of COVID-19 has brought unprecedented challenges to the medical community. Providing clinical care and maintaining public health are the obvious priorities, but other activities such as medical research and education cannot be neglected. Continuing high quality, evidence-based education to head and neck surgery trainees is more important than ever, as they may be required to join the work-force at an accelerated pace.

Here we provide an update on the current state of head and neck oncology and reconstructive surgical fellowship training and certification and how it has been impacted by the COVID-19 pandemic. In addition, we provide an overview of approaches used to augment surgical training that can be implemented even in environments of reduced patient contact. Last, we give perspective from the leadership of the Advanced Training Council (ATC) and Curriculum Development and Maintenance Service (CDMS), as well as the fellowship program directors and current trainees, to gain insight into potential gaps in education and training and outline current initiatives that are underway to ensure proficiency of those who will be completing this advanced training and entering the work-force in this unprecedented time.

\section{2 | METHODS}

The ATC in collaboration with AHNS leadership determined in early March 2020 that the match deadline for the July 2021 class would need to be delayed from June 2020 to at least September 2020. Senior members of the ATC (D. T. W. and A. C.) organized two separate phone conferences; the first with AHNS fellows on March
24, 2020 and the second with AHNS program directors on March 26, 2020. Follow-up online surveys were sent via email links to current AHNS fellows and AHNS program directors. The content of these calls and the focus of the survey questions included assessment of changes in didactic educational programs, impacts on current surgical and outpatient clinic experiences, assessment of fellow repurposing plans to meet anticipated needs related to COVID-19 patient surge, safety concerns regarding COVID-19, and impacts on this year's clinical fellows' job searches, including established and pending job offers.

Case $\log$ analysis was also performed to assess the impact of COVID-19 on the ability of current fellows to obtain adequate operative volume for certification. Values are based on data available in the online case log system administered by the ATC (data acquired between April 13 and 15, 2020). To supplement this data, the ATC also asked program directors and fellows to assess the trainee's preparedness to start independent practice at the time of the survey. Last, fellows were queried if they had secured an employment position to start at the completion of fellowship and if, and in what way, their career choices had been impacted by the current pandemic.

\section{3 | RESULTS}

\section{1 | Didactic education}

Twelve of 31 fellows (39\%) surveyed responded that programmatic changes had occurred in their didactic curriculum, with most respondents citing the increased use of online and video platforms for journal clubs, didactic lectures, and other clinical discussion groups. Thirty one of 32 fellows (97\%) reported weekly participation in the virtual tumor board series implemented by the CDMS faculty for head and neck fellows. Program director responses to similar questions included 21 of 37 (57\%) reporting programmatic changes to their didactic curriculum, also citing video platforms for conferencing as the most widely incorporated change. Thirty-seven of 38 program directors (97\%) were aware of the CDMS weekly tumor board series for fellows. 
T A B L E 1 Average operative volume of current (2019-2020) AHNS fellows as of April 1, 2020, compared to the year-end completion operative logs of the 2018 to 2019 AHNS fellows

\begin{tabular}{llllll}
$\begin{array}{l}\text { Fellowship year (number of } \\
\text { case logs analyzed) }\end{array}$ & Laryngectomy & $\begin{array}{l}\text { Radical } \\
\text { tonsillectomy }\end{array}$ & Parotidectomy & Thyroidectomy & $\begin{array}{l}\text { Microvascular } \\
\text { reconstruction }\end{array}$ \\
\hline $\begin{array}{l}2018-2019 \\
\mathrm{~N}=50\end{array}$ & $13(1-27)$ & $11(1-38)$ & $21(1-42)$ & $32(1-278)$ & $68(1-152)$ \\
$\begin{array}{l}2019-2020 \\
\mathrm{~N}=56\end{array}$ & $9(1-27)$ & $11(1-34)$ & $14(1-35)$ & $18(1-198)$ & $52(1-174)$ \\
\hline Comparison (\%) & 70 & 100 & 67 & 56 & 77 \\
\hline
\end{tabular}

\section{2 | Clinical training}

Of the 37 responses received from program directors, the majority (70\%) reported a $50 \%$ to $90 \%$ reduction in the number of elective cases at their institutions (March-April 2020). However, many (30 of 37, 81\%) also stated that their fellows were still participating in oncology cases and remained active in a variety of procedures. The only area that showed significant decline was in cases related to treatment of benign processes ( 9 of $37,24 \%$ still perform these operations). The majority of head and neck fellow-run clinics had been canceled (31 of $38,86 \%$ ), while a minority of fellows were given exposure to attending-run virtual or telemedicine clinics (8 of $31,26 \%$ ).

About half of current fellows (15) reported being available for airway emergencies. Four fellows (13\%) have been asked to be available for non-fellowship related clinical duties as part of their institution's surge planning for COVID-19. When asked if they had safety concerns regarding their institution's policy with regard to caring for patients with COVID-19 as it relates to their training, only a minority of fellows responded (10 of $32,31 \%)$ and only one reported safety concerns.

\section{3 | Credentialing}

In the current training year, the mean and median number of major head and neck operations logged by head and neck fellows were 329 and 364, respectively. Fifty of the 61 fellows (82\%), who logged any cases to the system, had already passed the 100 major head and neck procedures milestone. The average number of cases of the current fellows was compared to last year graduates in specific categories (Table 1). The majority of ATC program directors viewed their trainee as well prepared for independent practice ( 31 of $36,86 \%$ ). Additionally, the majority of current ATC fellows felt prepared for both ablative (25 of 26, 96\%) and reconstructive (19 of 26, 73\%) procedures. In the ATC survey of program directors, $43 \%$
(16 of 37) responded as open to consideration of extending the current fellowship by 3 months.

\subsection{Fellowship interviews and match}

The majority of program directors ( 21 of $38,55 \%$ ) agreed with the ATC's decision to delay the 2020 match by at least 3 months, and 25\% (10 of 38) were not certain if this delay would be long enough. No program surveyed had finished the interview process and a minority had set up tele interviews ( 7 of $38,18 \%$ ). The overwhelming majority of program directors (32 of 37, 86\%) surveyed did not anticipate challenges with the onboarding process of the new fellows beginning training in July 2020. A number of program directors suggested that the new fellows start in August instead of July.

\section{5 | Employment search}

Twenty-nine of 51 fellows responding reported having successfully secured a post fellowship appointment (57\%) while 22 (43\%) had not yet secured positions. Five fellows (10\%) reported that they had a position nearly secured or secured but that was now in question or on hold due to hiring freezes related to COVID-19. Ten fellows reported they were still actively interviewing for positions. Nine of 37 program directors $(25 \%)$ responded they would consider temporarily reappointing their fellow as an instructor beyond the end date of the fellowship year in order to support their transition to permanent employment elsewhere.

\section{4 | DISCUSSION}

The advanced, intensive, short period of head and neck surgical training brings specific challenges to its educators. The fellowship is generally 1 year and relies on exposure to a high number of clinical cases, structured 
learning in oncology, and gradual advancement in performing more complex operations. As can be seen from the survey results from both the fellows and the program directors, the immediate impact on the surgical case experience of this year's trainees have been substantial, with $70 \%$ of program directors reporting $50 \%$ to $90 \%$ reduction in elective cases. Robust fellow participation in cancer related surgical procedures has continued, however, with $81 \%$ of fellows reporting ongoing participation in these cases. A review of the surgical case logs of this year's fellows appears to support these results, as the case numbers for laryngectomy, radical tonsillectomy, and microvascular procedures have already reached $70 \%$ to $100 \%$ of the final volumes reported for the preceding year's fellowship class while parotidectomy and thyroidectomy (cases with mix of benign and malignant indications) lag somewhat behind (Table 1). Survey results suggest many fellow-run clinics have been curtailed. However, a minority of fellows are beginning to participate in telemedicine clinic experiences.

Successful completion of the AHNS head and neck fellowship has several requirements, all of which could be affected by the COVID-19 pandemic. Each fellow is required to directly participate in the evaluation and management of at least 200 patients with head and neck neoplastic disease, ${ }^{2}$ which should lead to the participation as either operative or teaching surgeon on at least 100 major head and neck surgical procedures. Analysis of the case logs of this year's fellows indicates that $82 \%$ of current fellows have already met this surgical benchmark. While this is certainly reassuring with regard to the current fellow class, the events of the COVID-19 pandemic provide a cautionary tale for future pandemics and how fellowship programs must be both nimble and creative with regard to their educational offerings and methods. Had pandemic conditions occurred earlier in the academic year, the impacts on surgical volumes would have likely been far more substantial.

The clinical impacts of COVID-19 may be perceived as the most obvious, and perhaps most acute with regard to fellowship training. But, social distancing and substantially altered scheduling routines have had a similarly profound impact on the didactics of the training programs. As summarized above, the majority of programs have quickly transitioned to online and video learning platforms, often alongside with their associated residency programs, and were able to rapidly adapt to these changes with robust ongoing educational offerings. Other external resources have simultaneously supplemented these didactic offerings, or may be available for programs to consider implementing. Such offerings may also be applicable to conditions of more severely curtailed surgical experiences.

\section{1 | AHNS initiated effort: virtual tumor board}

In response to the current transition to remote didactic learning, and based on the findings of a 2016 needs assessment study, the CDMS designed a virtual tumor board session with emphasis on education. The tumor board is run by the members of the CDMS and guest faculty from all areas of head and neck oncology. Case presentations are clinically oriented, and presented weekly with each week's three cases dedicated to a specific head and neck site. Discussions are interactive with faculty and fellows, but evidenced-based decision making is emphasized along with references for each management decision. The format is based on an interactive video platform that allows for realtime presentation of imaging, pathology slides, or literature references in addition to the live videos of the faculty discussants. The remote learning sessions were introduced in April of 2020. At the time of this writing, four sessions have been held. More than 50 participants have logged in during each session. As noted above, $97 \%$ of responding fellows have participated in at least one session and virtually all program directors are aware of the weekly tumor board (97\%). Plans are in place to continue this format and issue a survey after five sessions. If the response is encouraging, the virtual tumor board will continue until the end of the current academic year. Other formats such as structured lectures by faculty, journal club, and surgical video viewing sessions with commentary by the faculty, and also, active participation of the fellows are under consideration.

\subsection{1 | Online resources}

Internet-based solutions have proven valuable to supplement traditional bedside teaching and enhance both knowledge and technical skills. ${ }^{3}$ The majority of current surgical trainees have been exposed to virtual learning environments from an early age, are quick to adapt to these formats, ${ }^{4,5}$ and frequently incorporate online media in preparation for credentialing exams and clinical practice. ${ }^{6}$ Flipped classroom models have been demonstrated to improve performance. ${ }^{7}$ Current AHNS e-resources include standardized goals and objectives and recommended syllabus, ${ }^{8}$ as well as online journal clubs and surgical videos for regional and free flap harvests. In addition, high-quality open access materials are available. This content is highly valued in the developing world and is also commonly used by the US trainees. ${ }^{9}$ E-learning resources, especially those which are interactive, are highly accessible, updatable, and can, in some contexts, prove superior to traditional learning models in both user satisfaction and acquisition of surgical knowledge. ${ }^{10,11}$ 


\subsection{2 | Surgical simulation}

Surgical simulation allows students to learn and practice technical skills in a setting which permits time for reflection and discussion, without risk to patients, and in a pandemic, limits the risks to trainees and the broader community. Cadaveric or animal models may offer highly realistic platforms for training a range of surgical skills, but costs and facility requirements might limit their use and the transmission risk has not yet been studied. A range of physical and virtual reality (VR) simulators have been developed to address skills training in Oto-HNS. ${ }^{12}$ Physical simulators range from low complexity task trainers to high fidelity, 3D printed, models with anatomic and haptic feedback in all fields of surgery, and for all training levels. ${ }^{13} \mathrm{VR}$ simulation offers the ability not only to more accurately replicate complex anatomy, but also to introduce realistic pathology or mimic lifelike emergency situations. Existing VR environments applicable to head and neck surgical training include the da Vinci Skills Simulator, ${ }^{14,15}$ the Endoscopic Sinus Surgery Simulator (ES3), ${ }^{16,17}$ and a range of VR temporal bone drilling simulations. ${ }^{18-21}$

\subsection{3 | Nonsurgical skills}

Mastery of nontechnical skills (NTS) such as communication, teamwork, situational awareness, and decision making is critical to surgical training, but challenging in a remote learning environment. Multiple behavioral rating systems have been developed as frameworks for teaching and competency-based assessment of nontechnical surgical skills. The Non-Technical Skills for Surgeons system, Oxford NOTECHS II, and Observational Teamwork Assessment for Surgery have been widely employed across a range of surgical disciplines and environments. ${ }^{12,22,23}$ Although NTS assessment is most often employed in clinical settings, it can also be adapted to surgical simulations. ${ }^{24}$ Notably for head and neck surgical trainees, NTS training can be an integral component of simulated surgical emergencies. ${ }^{25}$

\subsection{4 | Live-feed surgery}

Surgical videos are excellent tools to be used during the pandemic, as they can walk trainees through the steps of complex surgeries. However, they do not offer the ability to interact, and often edit the "struggles" out of the videos. Similar to watching live surgery during medical conferences, the technology already exists to allow remote audiences to watch surgery and interact with the surgical team in real time. Wearing a head-mounted camera, the surgeon can broadcast a surgical-view of the operative field, and capture live video and audio to allow for a more interactive experience for the trainee. ${ }^{26}$

\subsection{5 | Virtual clinic visits/telemedicine proficiency}

Telehealth and virtual care are rapidly being integrated into most modern health care systems, a change that has been occurring even prior to the current pandemic. ${ }^{27}$ Within head and neck surgery, there is potential for telemedicine to replace a significant proportion of in-person office visits. ${ }^{28,29}$

Proficiency in use of telemedicine is therefore an increasingly important competency for all trainees. Fellowship directors can consider the current circumstances an opportunity to include mastery of telemedicine as an important learning objective. In our survey, only $26 \%$ of fellows reported participating in virtual clinics. Given that the majority of fellow-run clinics have been canceled, consideration should be made to replace these with virtual clinics. This would provide exposure to this important aspect of clinical practice and allow fellows to continue with real-time education in counseling, decision making, and systems-based practice.

This technology, however, is not without its limitations and pitfalls. Creating clear sets of guidelines for use of this technology will continue to add to its potential benefit and may serve as the foundation for postcrisis use of telemedicine. ${ }^{30}$

\section{2 | Clinical training and certification}

Successful completion of the AHNS head and neck fellowship has several requirements, all of which could be affected by the COVID-19 pandemic. Throughout the year, the trainee's performance is continually observed and assessed by the program director and faculty with semiannual formal evaluations and structured feedback provided on the trainee's performance. Prior to completing the fellowship, the program director provides an attestation of the trainee's performance and satisfactory completion of the training program. The ATC has the ultimate responsibility for certification of fellows enrolled in the accredited programs, with this certification depending upon a number of factors, perhaps the most important of which is the program director's final assessment of his or her fellow's readiness for program completion. With 3 months remaining in the training year $86 \%$ of responding program directors feel their trainees have already achieved readiness for independent practice as head and neck surgeons. Just as importantly, 96\% of responding fellows feel comfortable with their technical skills as ablative head and 
neck surgeons, and $73 \%$ have achieved similar levels of comfort with microvascular procedures. Moreover, in the current training year, $82 \%$ of fellows have already logged over 100 major head and neck operations. This analysis suggests that the current fellow class will comfortably achieve readiness for certification by the ATC by the completion of their fellowship year.

For any individual program whose educational experience may have been more adversely affected, the ATC would give careful consideration of a request to extend a fellow's experience. Extension of training is certainly not a straightforward "solution," however. Such an extension of training will raise many logistical concerns, including the extension of credentialing and malpractice coverage. Trainees and their families often have relocation plans and employment contracts that may not permit extension of training beyond June 30. Finally, the ATC and program director must consider the effect this will have on the clinical experience of the incoming fellow. Clear goals for satisfactory completion of training should be recommended and directed by each fellowship program as deemed necessary by the program director and teaching faculty, taking into consideration the individual needs, circumstances, and desires of the trainee. As with any training year, but particularly given the ongoing impacts of COVID-19 for this year, the ATC will review, provide guidance where necessary, and support requests for training extension in the best interests of its trainees.

\subsection{1 | Employment search}

In ATC survey of current fellows, 57\% stated that they had secured a post training position before the start of the pandemic. Over a third of the fellows were still in the interview process as the crisis developed. This is comparable to what is observed at this point in most fellowship cycles. The unprecedented impact of the COVID-19 pandemic on the operational priorities of health systems and institutions in the United States and Canada, however, has created uncertainty for those seeking jobs and the administrative leaders of institutions offering positions. It is possible that departments with new positions may be forced to delay or even withdraw their positions until the normal clinical care reopens. These conditions and their impact may even linger into the 2020 to 2021 academic cycle with indirect effects on the next year's graduates.

\subsection{2 | Study limitations}

Due to the fluid nature of the current COVID-19 crisis, many aspects of clinical care and education vary from day to day and also regionally within the North American AHNS training programs. In addition, due to the nature of survey collection, reporting bias is possible and operative log data may be inaccurate due to delays in entry or omissions by the current and past fellows. Efforts were made to interpret the best available data and to proactively make educational changes thought to enhance the current experience. Follow-up assessment will be needed to evaluate the effectiveness of these interventions.

\section{5 | CONCLUSION}

The COVID-19 pandemic has had a significant impact on the landscape of head and neck surgical training. With dramatic shifts in patient care being seen in nearly all geographic regions, a thoughtful and comprehensive approach to head and neck surgical training is needed to ensure proficiency of all graduates. Fortunately, due to the high clinical volume offered by accredited institutions, as well as enhanced educational experience provided through the standardized head and neck surgery fellowship curriculum, current trainees appear wellpositioned to achieve expertise before entering practice. As the length of this crisis extends, more opportunities to virtually or otherwise train our fellows will emerge. We expect this to remain a fluid set of recommendations, and the ATC and the CDMS of AHNS are prepared to remain flexible and accommodating to meet the needs of our community.

\section{ACKNOWLEDGMENTS}

The authors would like to thank JJ Jackman (American Head \& Neck Society) and Drs Jeffrey Liu (Temple University), Cheri-Ann Nathan (Louisiana State University, Shreveport), Susan McCammon (University of Alabama), Kris Mosier (University of Indiana), Alex Pearson (University of Chicago), and Elcin Zan (NYU Langone Health), for their incredible support and contributions.

\section{ORCID}

Babak Givi (i) https://orcid.org/0000-0002-8221-5077 Marc A. Cohen (D) https://orcid.org/0000-0002-6104-7967 Steven Kang (1) https://orcid.org/0000-0002-0865-6149 Andrew Shuman (10) https://orcid.org/0000-0002-93057860

Donald T. Weed (1) https://orcid.org/0000-0002-8551-7142

\section{REFERENCES}

1. The American Head and Neck Society. American Head \& Neck Society. 2020. https://www.ahns.info/about-ahns/. Accessed April 20, 2020. 
2. Advanced Training Council. ATC program guidelines for Head and Neck Fellowships. 2020. https://www.ahns.info/residentfellow. Accessed April 20, 2020.

3. Aloia A, Mullhaupt D, Chabbert CD, et al. A fatty acid oxidation-dependent metabolic shift regulates the adaptation of BRAF-mutated melanoma to MAPK inhibitors. Clin Cancer Res. 2019;25(22):6852-6867. https://doi.org/10.1158/1078-0432. CCR-19-0253

4. Larvin M. E-learning in surgical education and training. ANZ J Surg. 2009;79(3):133-137. https://doi.org/10.1111/j.1445-2197. 2008.04828.x

5. Martinelli SM, Isaak RS, Schell RM, Mitchell JD, McEvoy MD, Chen F. Learners and luddites in the twenty-first century: bringing evidence-based education to anesthesiology. Anesthesiology. 2019; 131(4):908-928. https://doi.org/10.1097/ALN.0000000000002827

6. Shabli S, Heuermann K, Leffers D, et al. Survey on the need for an e-learning-platform for ENT residents. Laryngorhinootologie. 2019;98(12):869-876. https://doi.org/10.1055/a-1025-2024

7. Moskowitz HS, Hsueh WD. Integrative resident education curriculum to adapt to the modern otolaryngology trainee. Laryngoscope. 2020;130(3):615-621. https://doi.org/10.1002/lary.28069

8. Curriculum Development and Maintenance Service. Goals \& Objectives. AHNS National Standardized Head \& Neck Fellowship Curriculum. 1st. 2018. https://www.ahns.info/wp-content/ uploads/2018/06/AHNS-HeadNeck-Fellowship-Curriculum6222018-hyperlinked.pdf. Accessed April 20, 2020.

9. Open Access Atlas of Otolaryngology, Head \& Neck Operative Surgery. 2020. http://www.entdev.uct.ac.za/guides/open-accessatlas-of-otolaryngology-head-neck-operative-surgery/. Accessed April 20, 2020.

10. Tarpada SP, Hsueh WD, Gibber MJ. Resident and student education in otolaryngology: a 10-year update on e-learning. Laryngoscope. 2017;127(7):E219-E224. https://doi.org/10.1002/lary.26320

11. Satterwhite T, Son J, Carey J, et al. Microsurgery education in residency training: validating an online curriculum. Ann Plast Surg. 2012;68(4):410-414. https://doi.org/10.1097/SAP.0b013e31823b6a1a

12. Javia L, Sardesai MG. Physical models and virtual reality simulators in otolaryngology. Otolaryngol Clin North Am. 2017;50 (5):875-891. https://doi.org/10.1016/j.otc.2017.05.001

13. Bur AM, Gomez ED, Newman JG, et al. Evaluation of highfidelity simulation as a training tool in transoral robotic surgery. Laryngoscope. 2017;127(12):2790-2795. https://doi.org/10. 1002/lary.26733

14. Zhang N, Sumer BD. Transoral robotic surgery: simulationbased standardized training. JAMA Otolaryngol Head Neck Surg. 2013;139(11):1111-1117. https://doi.org/10.1001/jamaoto. 2013.4720

15. Walliczek-Dworschak U, Schmitt M, Dworschak P, et al. The effect of different training exercises on the performance outcome on the da Vinci Skills Simulator. Surg Endosc. 2017;31(6): 2397-2405. https://doi.org/10.1007/s00464-016-5240-z

16. Edmond CV Jr. Impact of the endoscopic sinus surgical simulator on operating room performance. Laryngoscope. 2002;112(7 Pt 1): 1148-1158. https://doi.org/10.1097/00005537-200207000-00002

17. Fried MP, Sadoughi B, Gibber MJ, et al. From virtual reality to the operating room: the endoscopic sinus surgery simulator experiment. Otolaryngol Head Neck Surg. 2010;142(2):202-207. https://doi.org/10.1016/j.otohns.2009.11.023
18. Wiet GJ, Stredney D, Sessanna D, Bryan JA, Welling DB, Schmalbrock P. Virtual temporal bone dissection: an interactive surgical simulator. Otolaryngol Head Neck Surg. 2002;127 (1):79-83. https://doi.org/10.1067/mhn.2002.126588

19. Zirkle M, Roberson DW, Leuwer R, Dubrowski A. Using a virtual reality temporal bone simulator to assess otolaryngology trainees. Laryngoscope. 2007;117(2):258-263. https://doi.org/10. 1097/01.mlg.0000248246.09498.b4

20. Sewell C, Morris D, Blevins NH, et al. Providing metrics and performance feedback in a surgical simulator. Comput Aided Surg. 2008;13(2):63-81. https://doi.org/10.3109/10929080801957712

21. Zhao YC, Kennedy G, Yukawa K, Pyman B, O'Leary S. Can virtual reality simulator be used as a training aid to improve cadaver temporal bone dissection? Results of a randomized blinded control trial. Laryngoscope. 2011;121(4):831-837. https://doi.org/10.1002/lary.21287

22. Flin R, Youngson G, Paterson-Brown S, Rowley D, Maran N. The Non-technical Skills for Surgeons (NOTSS) System Handbook. Vol 1. 2. [1.2]. Scotland, UK: RCSed; 2012.

23. Robertson ER, Hadi M, Morgan LJ, et al. Oxford NOTECHS II: a modified theatre team non-technical skills scoring system. PLoS One. 2014;9(3):e90320. https://doi.org/10.1371/journal. pone.0090320

24. Magill JC, Tolley N. Non-technical skills simulation training. Curr Otorhinolaryngol Rep. 2020;8(1):106-110. https://doi.org/ 10.1007/s40136-020-00269-8

25. Wu KY, Kim S, Fung K, Roth K. Assessing nontechnical skills in otolaryngology emergencies through simulation-based training. Laryngoscope. 2018;128(10):2301-2306. https://doi.org/10. 1002/lary.27174

26. Silberthau KR, Chao TN, Newman JG. Innovating surgical education using video in the otolaryngology operating room. JAMA Otolaryngol Head Neck Surg. 2020;146:321. https://doi. org/10.1001/jamaoto.2019.4862

27. Deldar K, Bahaadinbeigy K, Tara SM. Teleconsultation and clinical decision making: a systematic review. Acta Inform Med. 2016;24(4):286-292. https://doi.org/10.5455/aim.2016.24. 286-292

28. McCool RR, Davies L. Where does telemedicine fit into otolaryngology? An assessment of telemedicine eligibility among otolaryngology diagnoses. Otolaryngol Head Neck Surg. 2018;158 (4):641-644. https://doi.org/10.1177/0194599818757724

29. Rimmer RA, Christopher V, Falck A, et al. Telemedicine in otolaryngology outpatient setting-single center head and neck surgery experience. Laryngoscope. 2018;128(9):2072-2075. https://doi.org/10.1002/lary.27123

30. Aman Prasad RMC, Rajasekaran K. Head and neck virtual medicine in a pandemic era: lessons from COVID-19. Head \& Neck. 2020. https://doi.org/10.22541/au.158594434.45036618

How to cite this article: Givi B, Moore MG, Bewley AF, et al. Advanced head and neck surgery training during the COVID-19 pandemic. Head \& Neck. 2020;42:1411-1417. https://doi.org/10.1002/ hed. 26252 